\title{
TYRAMINE-PRODUCING STREPTOCOCCI IN NEONATAL DIARRHOEA
}

\author{
BY \\ E. Y. BRIDSON AND JEAN BROWN* \\ From the Department of Pathology, Oldchurch Hospital, Romford, Essex
}

(RECEIVED FOR PUBLICATION NOVEMBER 11, 1959)

\begin{abstract}
An outbreak of neonatal diarrhoea associated with large numbers of Streptococcus faecalis var. zymogenes is described.

A follow-up survey showed that $23.3 \%$ of 347 healthy babies carried this organism without ill effect.

The tyrosine decarboxylase activity of the streptococci from both sick and healthy babies was identically high.

It is suggested that the tyramine-producing activity of these streptococci was not the primary cause of the diarrhoea.
\end{abstract}

Tyramine is similar to histamine and possesses powerful physiological actions. It is produced from the amino-acid tyrosine by decarboxylation. The enzyme capable of doing this is called tyrosine decarboxylase (Hawk, Oser, and Summerson, 1947).

Gale (1940) demonstrated that certain strains of Streptococcus faecalis could produce tyramine, and he later (Gale, 1944) described how he had found large numbers of $\beta$-haemolytic, group $D$ streptococci in the stools of infants involved in some outbreaks of neonatal diarrhoea. These streptococci had an unusually high tyrosine decarboxylase activity and when fed to infant rats resulted in a fatal diarrhoea. This syndrome could be imitated by feeding tyramine itself. Older rats were not susceptible to the action of either the organisms or the amine. He explained this by showing that tyramine oxidase was significantly deficient in infant tissue at birth but fully developed at the end of the third month.

Sharpe (1948) investigated 340 strains of streptococci from infants' faeces and estimated their tyrosine decarboxylase activities. She found that the Strep. faecalis varieties-faecalis, liquefaciens, and zymogenes - had a high carboxylase activity, whereas Strep. durans and Strep. bovis showed little activity.

Sharpe and Shattock (1952) typed serologically group D streptococci associated with outbreaks of neonatal diarrhoea. They listed 24 types and

*Present address: Department of Patholozy, Chase Farm Hospital, Enfield. three subtypes (five types of Strep. faecalis var. zymogenes).

Sharpe (1952) examined the streptococcal flora of faeces in eight outbreaks of neonatal diarrhoea associated with non-haemolytic group D streptococci. She suspected Escherichia coli were involved in some of the outbreaks.

\section{An Outbreak of Neonatal Diarrhoea at Oldchurch Hospital}

Fifteen newborn babies in one of three nursery wards were found to be suffering from diarrhoea with loose green stools. They showed some loss of weight but no obvious dehydration. Two of these 15 babies died during the investigation.

Stool cultures showed a marked predominance of group $\mathrm{D} \beta$-haemolytic streptococci with scanty growth only of $E$. coli, Proteus spp., and nonhaemolytic streptococci. Some of the cultures showed aerobic flora composed entirely of $\beta$-haemolytic streptococci. Table I shows the results of daily faecal cultures on 14 babies. The scanty growths of $E$. coli isolated were tested with E. coli $\mathrm{O} .55, \mathrm{O} .26$, and $\mathrm{O} .111$ antisera with negative results.

After 10 days the remaining babies were discharged. The ward was closed for a week and thoroughly cleaned.

Necropsy Findings.-One baby died at the onset of the investigation. The cause of death was acute pulmonary infection. Strep. faecalis 
TABLE I

GROWTH OF $\beta$-HAEMOLYTIC STREPTOCOCCI IN FAECAL CULTURES IN M.A. NURSERY

\begin{tabular}{|c|c|c|c|c|c|c|c|c|c|}
\hline & & & & & Date & & & & \\
\hline & & Mar. 4 & Mar. 5 & Mar. 6 & Mar. 7 & Mar. 8 & Mar. 9 & Mar. 10 & \\
\hline 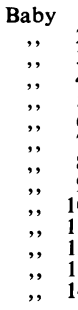 & $\begin{array}{ll}1 & \cdots \\
2 & \cdots \\
3 & \cdots \\
4 & \cdots \\
5 & \cdots \\
6 & \cdots \\
7 & \cdots \\
8 & \cdots \\
9 & \ldots \\
10 & \ldots \\
11 & \ldots \\
12 & \cdots \\
13 & \ldots \\
14 & \ldots\end{array}$ & $\begin{array}{c}++ \\
+++ \\
++ \\
+++ \\
+++ \\
++ \\
++ \\
+++ \\
++ \\
+++ \\
+++ \\
+++ \\
+++\end{array}$ & $\begin{array}{l}+++ \\
+++ \\
+++ \\
+++ \\
+++ \\
++ \\
+++ \\
\text { D } \\
+++ \\
+++ \\
+++ \\
+++ \\
+++ \\
+++\end{array}$ & 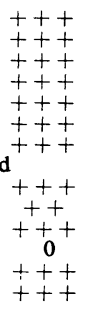 & $\begin{array}{c}++ \\
+ \\
++ \\
+++ \\
+++ \\
++ \\
+ \\
++ \\
0 \\
+++ \\
0 \\
++ \\
0\end{array}$ & $\begin{array}{c}+ \\
+ \\
+ \\
\pm \\
+ \\
++ \\
0 \\
\overline{+} \\
+ \\
0 \\
\text { ged Discha } \\
0 \text { Discha } \\
+++ \\
-\end{array}$ & $\begin{array}{c}+ \\
+ \\
\pm \\
0 \\
+++ \\
0 \\
- \\
d \\
\pm \\
\text { d }\end{array}$ & $\begin{array}{l}+ \\
++ \\
++ \\
0 \\
- \\
++ \\
++ \\
- \\
+ \\
++ \\
- \\
-\end{array}$ & ,", \\
\hline
\end{tabular}

Tc. =treated with chloramphenicol from Mar. $7 . \quad+=$ dezrez of growth of streptococci in the faecal culture, i.e., $t=1$ or 2 colonies $+=$ scanty growth. $++=$ moderate growth. $+++=$ profuse giowth $(60-10) \%$ total flora). $0=$ no growth of $\beta$-haemolytic streptococci. $-=$ no swab received.

TABLE II

BABIES IN NURSERY A.2 CARRYING $\beta$-HAEMOLYTIC STREPTOCOCCI IN FAECAL FLORA

\begin{tabular}{|c|c|c|c|c|c|c|c|c|c|c|c|c|c|c|}
\hline & & \multicolumn{13}{|c|}{ Date } \\
\hline & & Mar. 26 & Mar. 27 & Mar. 28 & Mar. 29 & Apr. 3 & Apr. 4 & Apr. 5 & Apr. 6 & Apr. 7 & Apr. 9 & Apr. 10 & Apr. 11 & Apr. 12 \\
\hline $\begin{array}{cc}\text { Baby } & \mathbf{A} \\
,, & \mathbf{B} \\
,, & \mathbf{C} \\
,, & \mathbf{D} \\
,, & \mathbf{E} \\
,, & \mathbf{F} \\
,, & \mathbf{G} \\
,, & \mathbf{H} \\
,, & \mathbf{I} \\
,, & \mathbf{J} \\
,, & \mathbf{K} \\
,, & \mathbf{L} \\
,, & \mathbf{M} \\
,, & \mathbf{N} \\
,, & \mathbf{O} \\
,, & \mathbf{P} \\
,, & \mathbf{Q}\end{array}$ & $\begin{array}{l}\ldots \\
\ldots \\
\ldots \\
\ldots \\
\ldots \\
\ldots \\
\ldots \\
\ldots \\
\ldots \\
\ldots \\
\ldots \\
\ldots \\
\ldots \\
\ldots\end{array}$ & $\begin{array}{c}0 \\
0 \\
0 \\
+++ \\
= \\
= \\
= \\
= \\
= \\
- \\
- \\
- \\
-\end{array}$ & $\begin{array}{c}0 \\
0 \\
0 \\
+++ \\
= \\
= \\
= \\
= \\
= \\
= \\
= \\
- \\
-\end{array}$ & $\begin{array}{c}0 \\
+ \\
0 \\
+++ \\
0 \\
+++ \\
= \\
= \\
= \\
= \\
= \\
=\end{array}$ & $\begin{array}{c}0 \\
0 \\
0 \\
+++ \\
0 \\
+++ \\
0 \\
++ \\
++ \\
0 \\
0 \\
+ \\
= \\
- \\
-\end{array}$ & $\begin{array}{c}- \\
++ \\
- \\
+ \\
+ \\
\overline{+} \\
+ \\
+ \\
0 \\
0 \\
0 \\
+ \\
++ \\
0 \\
0 \\
0\end{array}$ & $\begin{array}{c}-+ \\
- \\
\overline{-} \\
+ \\
++ \\
0 \\
0 \\
+ \\
0 \\
0 \\
0 \\
\pm \\
++ \\
0 \\
++ \\
0\end{array}$ & $\begin{array}{c}-0 \\
- \\
- \\
++ \\
++ \\
0 \\
++ \\
0 \\
0 \\
0 \\
0 \\
+ \\
++ \\
0 \\
+ \\
0\end{array}$ & $\begin{array}{c}- \\
\overline{-} \\
\overline{-} \\
\overline{0} \\
++ \\
++ \\
0 \\
0 \\
0 \\
0 \\
++ \\
0 \\
0 \\
0\end{array}$ & $\begin{array}{c}- \\
\bar{Z} \\
\bar{Z} \\
\overline{-} \\
++ \\
\overline{-} \\
\pm \\
0 \\
++ \\
0 \\
0 \\
0\end{array}$ & $\begin{array}{c}- \\
\bar{z} \\
\bar{z} \\
\overline{-} \\
++ \\
\overline{0} \\
++ \\
- \\
++ \\
++ \\
0 \\
0 \\
0\end{array}$ & $\begin{array}{l}- \\
z \\
z \\
z \\
z \\
\bar{z} \\
+ \\
+ \\
++ \\
+ \\
+\end{array}$ & 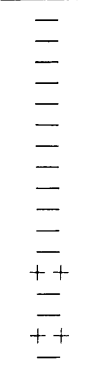 & 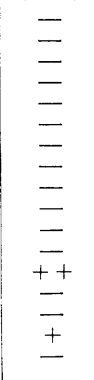 \\
\hline
\end{tabular}

$\begin{aligned}+ & =\text { degree of growth of streptococci in the faecal culture, i.e., } \pm=1 \text { or } 2 \text { colonies. }+=\text { scanty growth. } \\ +++ & =\text { profuse growth }(60-100 \% \text { total flora }) . \quad 0=\text { no growth of } \beta \text {-haemolytic streptococci. } \quad-=\text { no swab received. }\end{aligned}$

var. zymogenes was grown from the bronchus. The small gut appeared pink and inflamed, but no $\beta$-haemolytic streptococci were grown from it.

The second baby died six days later. The cause of death was multiple focal necroses of the liver, probably secondary to umbilical sepsis.

Epidemiological Investigation.-In the remaining two nursery wards rectal swabs from the babies were examined daily for evidence of $\beta$-haemolytic streptococci.

A sample of the results obtained from one nursery is shown in Table II.

Later it was decided to swab the babies from all three nurseries once only, on discharge. By the end of four months, 347 babies had been investigated. None of these babies showed evidence of enteritis (Table III).
TABLE III

RESULT OF INVESTIGATION OF FAECAL FLORA IN 347 HEALTHY BABIES

\begin{tabular}{|c|c|c|c|}
\hline Ward & $\begin{array}{l}\text { No. of } \\
\text { Babies }\end{array}$ & $\begin{array}{c}\text { No. of Babies } \\
\text { with } \\
\text { Group D } \\
\text { Haemolytic } \\
\text { Streptococci }\end{array}$ & $\begin{array}{l}\text { No. of Babies with } \\
\text { Profuse Growth } \\
\text { of Group D } \\
\text { Haemolytic } \\
\text { Streptococci }\end{array}$ \\
\hline $\begin{array}{l}\text { M.A. } \\
\text { A.1 } \\
\text { A. } 2\end{array}$ & $\begin{array}{l}132 \\
104 \\
111\end{array}$ & $\begin{array}{l}27(20.5 \%) \\
24(23.1 \%) \\
30(27.0 \%)\end{array}$ & $\begin{array}{r}16 \\
7 \\
12\end{array}$ \\
\hline Total & 347 & $81(23.3 \%)$ & $32(9 \cdot 2 \%)$ \\
\hline
\end{tabular}

No further occurrence of diarrhoea was reported in the discharged group of affected babies. The investigation was closed after five months.

Bacteriology. - The haemolytic streptococci isolated from the 15 babies involved in the outbreak of diarrhoea were confirmed as Strep. 
faecalis var. zymogenes by the Streptococcal Reference Laboratory, Colindale.

The 81 strains of $\beta$-haemolytic streptococci isolated from the healthy babies were examined for their biochemical reactions in parallel with the 15 strains of streptococci isolated from the affected babies.

All 96 strains of streptococci were identified serologically as group D. All showed growth at $p \mathrm{H} 9.6$ and grew in broth containing $6.5 \% \mathrm{NaCl}$. All strains fermented mannite and sorbitol and failed to ferment arabinose and raffinose in serumwater media.

All the strains were heat resistant when tested for 30 minutes at $60^{\circ} \mathrm{C}$. and they all grew on MacConkey agar.

The strains were all resistant to tellurite when grown on blood agar containing a final concentration of $1 / 2,500$ potassium tellurite.

All 96 strains showed variable results in the liquefaction of gelatin and the fermentation of glycerol.

The 15 strains isolated from the affected group of babies showed one antibiotic sensitivity pattern, namely, sensitive to chloramphenicol and erythromycin, insensitive to penicillin, streptomycin, and the tetracyclines.

Of the remaining 81 strains, isolated from healthy babies, 25 strains showed this same pattern and 56 strains showed varying antibiotic sensitivity patterns.

The tyrosine decarboxylase activity of the streptococci was estimated by the method of Gale, as described by Sharpe (1948). Sharpe found that minute variations in the medium caused considerable $p \mathrm{H}$ differences and she tested each batch of medium with a reference strain of Strep. faecalis obtained from Gale, which under test conditions gave a difference of $1.5-1.8 p \mathrm{H}$ units.

A strain of Streptococcus faecalis from the National Collection of Industrial Bacteria (N.C.I.B. 6783), which had been deposited by Gale as a reference strain for the estimation of tyrosine decarboxylase, was examined. In our media, this strain, under test conditions, gave a difference of $1.47 \mathrm{pH}$ units.

All 96 strains of haemolytic streptococci isolated showed a high tyrosine decarboxylase activity.

The streptococci isolated from the 15 affected babies showed activities varying from 1.78 to 2.31 $p \mathrm{H}$ units. The streptococci isolated from the 81 healthy babies showed activities varying from 1.78 to $2.42 \mathrm{pH}$ units.

Serological typing of the group D streptococci was not carried out.

\section{Discussion}

This outbreak of neonatal diarrhoea closely paralleled the outbreaks described by Gale (1944) inasmuch as a group of babies with diarrhoea was found to be excreting large numbers of $\beta$-haemolytic group D streptococci.

Gale's hypothesis that the diarrhoea of the babies was caused by the tyramine produced by the predominantly streptococcal faecal flora seemed very probable, and the probability seemed to be stronger when it was discovered that the streptococci, in this outbreak, had a high tyrosine decarboxylase activity.

But further examination of the faecal flora in all the babies born in this hospital over a period of four months showed that large numbers of these babies carried Strep. faecalis var. zymogenes in their faeces without ill effect. The tyrosine decarboxylase activity was as high in these streptococci as it was in the streptococci isolated from the infected babies. The varying antibiotic sensitivity patterns of these organisms suggested that more than one serological type of streptococci was carried.

The record of daily faecal cultures on one group of babies (extracted in Table II) showed that this organism usually established itself in the first or second day of the infant's life. The babies who had escaped infection by then usually remained free from the organism for the remainder of their stay in hospital (10 days).

None of the outbreaks of neonatal diarrhoea investigated by Sharpe (1952) had $\beta$-haemolytic streptococci as the predominant faecal flora. Only one outbreak investigated showed a marked prevalence of non-haemolytic group D streptococci.

Sharpe was not able to come to any definite conclusion and suggested: (1) That diarrhoeal conditions may have favoured the establishment of this type of streptococcus (tyramine producer) already present in small numbers in the intestine. (2) Unfavourable factors in managing infants may have rendered the gut particularly susceptible to this organism and their increased numbers may have caused the diarrhoea, possibly by means of the increased amount of tyramine produced by the almost pure streptococcal flora.

From the findings in our investigation it would appear that the carriage in the faecal flora of large numbers of highly active, tyramineproducing streptococci does not necessarily lead to diarrhoea and that some other factor or factors must be involved. Ross (1951) found that the tyrosine content of the large bowel in newborn babies is negligible. 
It is possible that in this outbreak of diarrhoea the babies could have been accidentally fed large quantities of the organism by mouth, as Gale (1944) fed his young rats. Sharpe also considered this possibility and suspected the glucose-water which she could not check. We tested the glucose, teats, and bottles used, but found no streptococci present. Mothers of the babies and hospital staff associated with these babies were examined, but showed no evidence of group $D \beta$-haemolytic streptococcal infection.

The deaths of the two babies in the outbreak were undoubtedly due to systemic infection by the predominant organism in their heavily infected environment. The post-mortem appearances were characteristic of a systemic invasion by an organism of low virulence.
Grateful thanks are expressed to the Director of the laboratory, Dr. E. A. Atkinson, for his encouragement and for his necropsy reports which he made freely available.

We are also grateful to the Curator, National Collection of Industrial Bacteria, for helpful advice and for the reference strain of streptococci.

Without the hard work and co-operation of the staff of the Maternity Unit this work could not have gone forward.

\section{REFERENCES}

Gale, E. F. (1940). Biochem. J., 34, 846.

- (1944). Lancet, 1, 568.

Hawk, P. B., Oser, B. L., and Summerson, W. H. (1947). Practical Physiological Chemistry, 12th ed. Blakiston, New York.

Ross, Constance A. C. (1951). Lancet, 2, 190.

Sharpe, M. Elisabeth (1948). Proc. Soc. appl. Bact., p. 13.

- (1952). J. Hyg. (Lond.), 50, 209.

—_ and Shattock, P. M. Frances (1952). J. gen. Microbiol., 6, 150. 